\title{
Kindness and competition: Are we striking the right balance in medical
}

\section{education?}

\author{
David J Brewster ${ }^{1,2,3}$, Charlotte E Rees ${ }^{1}$, Michelle Leech ${ }^{4}$, and Geoff Thompson ${ }^{4}$
}

1. Monash Centre for Scholarship in Health Education (MCSHE), Faculty of Medicine, Nursing \& Health

Sciences, Monash University, Victoria, Australia

2. Cabrini Hospital, Victoria, Australia

3. Central Clinical School, Faculty of Medicine, Nursing \& Health Sciences, Monash University, Victoria, Australia

4. Faculty of Medicine, Nursing \& Health Sciences, Monash University, Victoria, Australia

\section{COMMENTARY}

Please cite this paper as: Brewster DJ, Rees CE, Leech $M$, Thompson G. Kindness and competition: Are we striking the right balance in medical education? AMJ 2018;11(5):313-315. https://doi.org/10.21767/AMJ.2018.3440

\section{Corresponding Author:}

A/Professor David Brewster

Monash Centre for Scholarship in Health Education (MCSHE)

Faculty of Medicine, Nursing \& Health Sciences

Monash University, Victoria, Australia

Email: dbrewster@cabrini.com.au

Many parents could be excused for no longer hoping that their children pursue careers in medicine. Junior medical staff must cope with unforgiving rosters that often include rigorous on-call commitments and night shifts. Coupled with this, they face the emotional challenges of caring for very sick patients and their families. ${ }^{1}$ In addition, recent reports of bullying and harassment from the specialty colleges indicate that hospitals continue to be imperfect workplaces. ${ }^{2}$

In 2015, the Royal Australian College of Surgeons (RACS) Expert Advisory Group found that 49 per cent of fellows, trainees and international medical graduates reported experiencing discrimination, bullying or sexual harassment, and 71 per cent of hospitals reported discrimination, bullying or sexual harassment in their hospital in the last five years. ${ }^{2}$ By late 2016, the College of Intensive Care Medicine (CICM) had reported an unacceptable prevalence of both bullying and discrimination (32 per cent and 12 per cent respectively) within their workforce. ${ }^{3}$ This followed a previous study in intensive care medicine that reported high rates of psychological stress (80 per cent) and emotional exhaustion (42 per cent) amongst the medical staff. ${ }^{4}$ These high reported rates of bullying, discrimination and harassment are being experienced by an already stressed group of practitioners; and are coming from colleagues within a profession that purports to value care and compassion.

Workplace stress has been cited as a contributor to the recently reported mental health concerns experienced by our medical community. ${ }^{5}$ In 2013, beyondblue reported an epidemic of burnout ( 35 per cent to 47 per cent) and cynicism (36 per cent to 46 per cent) amongst junior doctors. ${ }^{5}$ It also reported a high rate of suicidal ideation (24 per cent in the past 12 months) in doctors compared to the general population (13 per cent). More recently, the psychological distress felt by our junior practitioners has seen an escalating number of junior doctors commit suicide. ${ }^{6}$ As others have suggested, it is time for reflection by the medical community. For a profession that has care and compassion at its core, there is some irony in our inability to express care for each other.

It is worth discussing the pathway from basic medical training to employment as a junior doctor in Australia. We start by ranking our high school graduates with precise scores to help distinguish between applicants of likely equal academic aptitude. Only a few of those capable can be considered for entry into medical school. In some states, such as Victoria, medical school training culminates in a final percentile score to allow further ranking and comparison by hospitals for the purpose of intern selection. ${ }^{7}$ Afterwards, many specialty colleges rigorously compare the curriculum vitae of junior doctors when ranking their suitability to enter into training programs. Employer health services use similar approaches for highly coveted training jobs. 
We would argue that such competitive educational and workplace environments propagate a bruising culture of competition; a culture that neither engenders nor motivates peer support or compassion. Such competition, coupled with training congestion, threatens professional identity and connectedness. Indeed, any culture of collegiate relationships is under threat. Such collegiate relationships not only facilitate the teamwork of good healthcare delivery but should also protect us from the stresses inherent in practicing medicine.

When culture is at the heart of the problem, do we need to step back and re-think? There have been suggestions that we need to change roster patterns to allow flexibility and to ensure we have employee assistance programs within our hospitals. ${ }^{8}$ Indeed, a great deal of work has been done in recent years to reduce the working hours of many junior doctors. But is this the answer, or just a "band aid" solution for a deeper wound? Medical students and junior doctors have developed 'antibodies' to calls from their seniors for greater resilience, and see this as a refusal to accept the need for cultural change. While promoting resilience may be good, excessive focus on individual resilience leads those who are feeling stressed to believe that they have failed their mindfulness training and could act as a barrier to acknowledging stress and seeking help. Rather than teaching our doctors to withstand a competitive landscape, we should instead be encouraging them to look after themselves and each other. ${ }^{9}$

How do we reduce competition, as well as model and incentivize compassion amongst our students and recent graduates? One approach could be to cease giving students any grades: they could simply 'pass' or 'fail'. Opponents to this system would argue that grading provides the motivation for hard work to achieve better learning and allows the faculty to identify medical students in need of remedial education. ${ }^{9}$ However, removing such grading has not been shown to be detrimental to graduate performance and does reduce competition. ${ }^{10}$ We could then reward collaboration and teamwork through shifting our focus towards group (instead of individual) assessment. But is such a change possible in Australia, where the hospital intern selection system in most states is based on academic ranking in order to compare our graduates?

It is interesting to ponder how our profession has fostered such competition. It may be more important to assess the basic competency of our students, against an agreed minimum level of excellence, rather than ranking each student beyond that standard of performance. Patients do not ask to see the academic ranking or transcript of the doctor who is caring for them. Does ranking beyond an agreed level of excellence predict the quality of future medical practice or capacity to withstand the pressures of the profession? This competition does not appear to have any benefits for the actual practice of medicine, and yet is contributing to the fragile state of our junior doctor workforce.

Over the past decade, medical educators have debated the right balance of basic and social sciences, communication skills and anatomy training in medical courses. Many courses now include approaches to empathy, growth mindsets, and medical humanities. In many professions, it is increasingly recognized that education should extend beyond skills and competencies. We should also target capabilities. ${ }^{11}$ The challenge of creating authentic assessments for these capabilities is one that we should not avoid. Whilst it is a daunting task to consider how one may assess kindness, compassion, respect and professionalism, we may be able to learn from other professions that have begun to recognize and value the inclusion of these capabilities in their education strategy. ${ }^{12,13}$ Indeed, interprofessional education focusing on kindness could provide the conduit to change by creating a collaborative atmosphere that helps generate student support. ${ }^{14}$

It was pleasing to recently read Catherine Crock's insight about changing the culture within hospitals to create a "kind heath system", one where we look after each other and "provide support and assistance with kind behaviours" ${ }^{15}$ At times, the challenges facing the medical profession, extending from our healthcare services, can seem overwhelming. This can create a sense of disillusionment about giving due consideration to doctor and medical student ill health and cultural change. The dialogue has a certain resignation that change is unlikely, either from a top-down or bottom-up approach. Maybe medical students and junior doctors are not powerful enough to influence prevailing medical cultures.

However, please do not lose faith. Multiple, repeated, random and deliberative acts of kindness may have extraordinary short-term impacts on a larger scale. These may create hope. Hope is a powerful emotion, which can generate a sense of future and possibility, and subsequently support coping, healing and recovery. Our healthcare system needs this as much as our patients. III heath amongst doctors is known to adversely effect patient care and a need for more self-compassion has been described. ${ }^{16}$ Replacing fierce competition with a culture of kindness among medical students and doctors 
should ultimately lead to kindness, compassion and hope for our patients. Simple acts of kindness can be intergenerational; they are inexpensive, easy to perform and ultimately augment resilience.

The culture of the past is not serving our younger colleagues well. Currently, there is a strong need for intergenerational reflection in medicine. Recently, junior doctors have pleaded for specialty colleges to stand up and lead workplace reform by tackling harassment and bullying within medicine. ${ }^{17}$ Further workplace change is required to reduce competition, acknowledge the diverse and divisive interpretations of words like 'resilience', and to enable kindness amongst our profession. We need to help students foster their future leadership capabilities so that they can learn to offer protection, shelter and support to each other. This is undoubtedly a difficult task. We need to change the culture of unhealthy competition to have any chance of developing a new culture of compassion and kindness. Only from a new supportive environment would we be able to effectively tackle the deeper issues around mental health in our profession.

\section{References}

1. Lundin RM, Bashir K, Bullock A, et al. I'd been like freaking out the whole night: exploring emotion regulation based on junior doctors' narratives. Adv Health Sci Educ. 2018;23:7-28.

2. Crebbin W, Campbell G, Hillis DA, et al. Prevalence of bullying, discrimination and sexual harassment in surgery in Australasia. ANZ J Surg. 2015;85(12):905-909.

3. Venkatesh B, Corke C, Raper R, et al. Prevalence of bullying, discrimination and sexual harassment among trainees and Fellows of the College of Intensive Care Medicine of Australia and New Zealand. Crit Care Resusc. 2016;18(4):230-234.

4. Shehabi Y, Dobb G, Jenkins I, et al. Burnout syndrome among Australian intensivists: a survey. Crit Care Resusc. 2008;10:312-315.

5. Beyond Blue National Mental Health Survey of Doctors and Medical Students Executive summary (October 2013). Accessed November 2017 via https://www.beyondblue.org.au/docs/defaultsource/research-project-files/bl1148-report---nmhdmssexec-summary_web.pdf?sfvrsn=4

6. Our Junior Doctor Suicide Crisis. Accessed November 2017 via http://www.dailytelegraph.com.au/news/nsw/juniordoctor-suicides-at-least-20-lives-lost-due-to-enormouspressure/newsstory/62606951f02d37f6365f6f00e4f492c2

7. The Intern Z Score. Accessed April 2018 via http://mscv.org.au/internshipgeneral/internz-score/

8. Simpson $\mathrm{N}$, Knott $\mathrm{Cl}$. Stress and burnout in intensive care medicine: an Australian perspective. Med J Aust. 2017;206(3):107-108.

9. Gonella J. An empirical study of the predictive validity of number grades in medical school using 3 decades of longitudinal data: implications for a grading system. Med Educ. 2004;38(4):425-434.

10. White CB, Fantone JC. Pass-fail grading: laying the foundation for self-regulated learning. Adv Health Sci Educ. 2010;15:469-477.

11. Fraser FW, Greenhalgh T. Coping with complexity: educating for capability. BMJ. 2001;323(7316):799803.

12. Richardson C, Percy $M$, Hughes J. Nursing therapeutics: Teaching student nurses care, compassion and empathy. Nurse Educ Today. 2015;35(5):e1-e5.

13. Brunero $S$, Lamont $S$, Coates $M$. A review of empathy education in nursing. Nurs Inq. 2010;17(1):65-74.

14. Monrouxe LV, Rees CE. Healthcare Professionalism: Improving Practice Through Reflections on Workplace Dilemmas. Oxford: Wiley-Blackwell 2017.

15. Crock C. Patient, staff safety and wellbeing: time for kindness. MJA InSight. 2017;35. Accessed November 2017 via https://www.doctorportal.com.au/mjainsight/2017/3 5/patient-staff-safety-and-wellbeing-time-forkindness

16. Mills J, Chapman M. Compassion and self-compassion in medicine: Self-care for the caregiver. AMJ 2016; 9(5):87-91

17. Jamieson J, Mitchell R, Le Fevre J, et al. Bullying and harassment of trainees: An unspoken emergency. EMA. 2015;27:464-467.

\section{PEER REVIEW}

Peer reviewed.

\section{CONFLICTS OF INTEREST}

The authors declare that they have no competing interests.

\section{FUNDING}

None

\section{ETHICS COMMITTEE APPROVAL}

Not applicable. 